\title{
Frequency of intake and amount of fluoride in milk for remineralisation of artificial caries on enamel and dentine: Ex vivo/in situ study
}

\author{
Luiza Cassiano, DDS, MS, PhD student in Oral Biology ${ }^{\mathrm{a}}$, Juliano Pessan, Assistant Professor ${ }^{\mathrm{b}}$, \\ Livia Comar, Adjunct Professor ${ }^{c}$, Flavia Levy, DDS, MS, PhD in Oral Biology ${ }^{\mathrm{a}}$, \\ Cristiane Cardoso, Assistant Professor ${ }^{\mathrm{d}}$, Aline Dionisio, MS student in Oral Biology ${ }^{\mathrm{a}}$, \\ Michele Manarelli, DDS, MS, PhD in Pediatric Dentistry ${ }^{\mathrm{b}}$, \\ Larissa Grizzo, Laboratory Specialist ${ }^{\mathrm{a}}$, Ana Carolina Magalhães, Associate Professor ${ }^{\mathrm{a}}$, \\ Marília Buzalaf, Full Professor ${ }^{\mathrm{a}, *}$ \\ a Department of Biological Sciences, Bauru School of Dentistry, University of São Paulo, Bauru, SP, Al. Octávio Pinheiro Brisolla, 9-75, Bauru, SP, 17012-901, \\ Brazil \\ ${ }^{\mathrm{b}}$ Araçatuba Dental School, UNESP - Univ Estadual Paulista, Araçatuba, SP, R. José Bonifácio, 1193, Araçatuba, SP, 16015-050, Brazil \\ ' School of Dentistry, Univ. Cidade de São Paulo (UNICID), R. Cesário Galeno, 448/475, São Paulo-SP, 03071-000, Brazil \\ d Institute of Dentistry, Cruzeiro do Sul University, R. Galvão Bueno, 868, São Paulo-SP, 01506-000, Brazil
}

\section{A R T I C L E I N F O}

\section{Article history:}

Received 26 May 2016

Received in revised form 6 October 2016

Accepted 11 October 2016

\section{Keywords:}

Enamel

Dentine

Fluoride

Milk

Remineralisation

Caries

\begin{abstract}
A B S T R A C T
Objectives: This study analysed the effect of frequency of intake and amount of fluoride in milk on the remineralisation of artificial enamel and dentine caries lesions ex vivo/in situ.

Materials and methods: Pre-demineralised bovine enamel and dentine slabs were randomly allocated into 5 groups and fixed in removable appliances used by subjects for 7 days in each phase. Each treatment comprised milk containing $2.5 \mathrm{ppm}$ fluoride daily (T1), or every other day (T2), $5.0 \mathrm{ppm}$ F daily (T3), or every other day (T4) or no treatment (T5).

Results: Enamel alterations were quantified by surface hardness recovery (\%SHR) and transversal microradiography (TMR), and in dentine by TMR only. Data were analysed by ANOVA and Tukey's test $(\mathrm{p}<0.05)$. For enamel, the highest \%SHR was found for T1 and T3 compared to control, without significant differences between them. All groups showed positive values of $\Delta \Delta Z-\mathrm{T} 1$ (247.3 \pm 198.5$)$; T2 $(110.9 \pm 303.2)$; T3 $(226.0 \pm 299.2)$; T5 $(5.0 \pm 288.0)$, except T4 $(-274.5 \pm 407.3)$. For dentine, the only group that presented remineralisation was T2 $(350.0 \pm 657.5)$.

Conclusions: Fluoridated milk daily seems to have higher remineralising effect on enamel than its use every other day. Dentine, does not seem to benefit from daily use of fluoridated milk.
\end{abstract}

(c) 2016 Published by Elsevier Ltd.

\section{Introduction}

Fluoride is considered the main responsible for the dramatic decrease in caries incidence and prevalence observed worldwide over the last decades (Bratthall, Hansel-Petersson, \& Sundberg, 1996). It can be administered by community, self-applied and professional methods, which are often used in association (Pessan, Toumba, \& Buzalaf, 2011). Water fluoridation has been regarded as

\footnotetext{
* Corresponding author.

E-mail addresses: luiza.cassiano@usp.br (L. Cassiano), jpessan@foa.unesp.br (J. Pessan), liviacomar@yahoo.com.br (L. Comar), flalevy@usp.br (F. Levy), crisbaldini@usp.br (C. Cardoso),stars_line@hotmail.com (A. Dionisio), michelemanarelli@gmail.com (M. Manarelli), larissagrizzo@yahoo.com.br (L. Grizzo), acm@fob.usp.br (A.C. Magalhães), mbuzalaf@fob.usp.br (M. Buzalaf).
}

the main primary preventive and public health measure for caries control, as it reaches most of the population, including socially deprived groups. The benefits of water fluoridation, however, are unavailable to a large proportion of the world's population, mainly due to political, geographical and technical reasons (Sampaio \& Levy, 2011). In order to overcome this problem, other methods of community fluoridation have been suggested. As milk is an important part of children's diet, fluoridated milk has been used in school-based preventive programmes for many decades, in different parts of the world. One of the main advantages of this method is that it allows the delivery of a precise amount of fluoride under controlled conditions (Banoczy, Rugg-Gunn, \& Woodward, 2013).

The effectiveness of fluoridated milk in caries control has been assessed by in vitro, in situ and clinical studies, which show a 
positive effect of its regular consumption on caries prevention (Banoczy et al., 2013). However, while the evidence of water fluoridation in caries control has been firmly established over the last decades (McDonagh et al., 2000), systematic reviews have concluded that the number of studies with good quality that evaluated the effects of fluoridated milk in preventing caries is insufficient. Overall, the included studies suggested that fluoridated milk was beneficial to school children, to prevent caries in the permanent (Yeung et al., 2005) or primary (Cagetti, Campus, Milia, \& Lingstrom, 2013) dentitions. High-quality studies, nonetheless, are still necessary in order that unequivocal evidence can be established. In addition, many aspects involving the milk fluoridation programmes still need to be addressed.

There are distinct ongoing school based milk fluoridation programmes worldwide in countries like Chile, Thailand, UK, Russia, Bulgaria and Republic of Macedonia, involving over a million children. These fluoridated milk schemes comprise a single drink of cow's milk at school during a morning break. However, the amount of fluoride delivered through milk in these programmes ranges between 0.5 and $0.85 \mathrm{mg}$ per day (Banoczy et al., 2013). Also the frequency of fluoridated milk consumption varies in the different milk fluoridation schemes. In the UK, the amount of fluoride delivered from milk is $0.5 \mathrm{mg}$ per day on school days (200 days/year), while in Chile quantities ranging between 0.25 and $0.75 \mathrm{mg}$ per day (depending on the age of the children) are delivered 365 days each year (Banoczy et al., 2013).

The impact of these differences in the amount of fluoride delivered and frequencies of intake on the caries preventive potential of milk fluoridation schemes is not completely known. The influence of two different fluoride concentrations in milk (2.5 and $5.0 \mathrm{ppm}$, corresponding to 0.5 and $1.0 \mathrm{mg}$ fluoride delivered in $200 \mathrm{~mL}$ of milk, respectively) on the prevention of demineralisation of sound enamel was recently evaluated in situ. Both fluoride concentrations significantly protected enamel from demineralisation when compared with non-fluoridated milk, but did not significantly differ from each other (Malinowski, Duggal, Strafford, \& Toumba, 2012a). A recent in vitro study evaluated the effect of different fluoride concentrations in milk $(2.5,5.0$ or $10.0 \mathrm{ppm})$ and also of distinct frequencies of use (once daily, twice daily or on alternate days) for remineralising initial enamel carious lesions. The best remineralising effect was observed for $2.5 \mathrm{ppm}$ fluoride milk used twice daily (Ongtenco et al., 2014). Regarding dentine, an in vitro study analysed the remineralising effect of different solutions (sodium chloride, artificial saliva, milk, milk $+2.5 \mathrm{ppm}$ fluoride, milk $+10 \mathrm{ppm}$ fluoride and artificial saliva $+10 \mathrm{ppm}$ fluoride). The results showed a positive effect of the fluoridated milk, but the group treated with sodium chloride presented a better effect (Arnold, Heidt, Kuntz, \& Naumova, 2014). However, only one in situ study evaluated the influence of different fluoride concentrations in milk on enamel remineralisation, but the quantities of fluoride used added in milk ( 1.5 or $3.0 \mathrm{mg}$ ) were higher than those typically employed in milk fluoridation schemes and the authors evaluated only surface rehardening (Lippert, Martinez-Mier, \& Zero, 2014).

In addition, to date no studies evaluated the effect of distinct fluoride concentrations in milk on dentine remineralisation in situ neither the effect of frequencies of use of milk on the remineralisation of dentine and enamel caries in situ. Thus, the present study evaluated if there was any additional benefit of increasing the amount of fluoride in milk from $2.5 \mathrm{ppm}$ to $5 \mathrm{ppm}$ per day on ex vivo/in situ enamel and root dentine remineralisation. The effect of different frequencies of drinking fluoridated milk (every day or every other day) was also investigated. It was hypothesized that higher fluoride concentration and frequency of milk intake would lead to enhanced remineralisation of enamel and dentine.

\section{Materials and methods}

\subsection{Ethical aspects and subjects}

The study followed a double-blind, randomised, crossover protocol, comprising 5 phases of 7 days each, with an interval of 7 days among them. Twenty-three young adult subjects ( 2 male, 21 female) took part in the study, after approval by the IRB of Bauru Dental School, University of São Paulo, Brazil (No.179/2011). Sample size was based on an in situ study recently conducted with similar research protocol (Malinowski et al., 2012a). According with that study, a sample size of 12 volunteers would be needed, in order to find a significant difference between the negative control ( $\mathrm{T} 5$ - no treatment) and milk containing $5.0 \mathrm{ppm}$ of fluoride, considering an $\alpha$ value of 0.05 and $80 \%$ of power. Considering possible dropouts, our study began with 25 volunteers, with 5 volunteers in each phase. The inclusion criteria were: stimulated salivary flow $>1 \mathrm{~mL} / \mathrm{min}$, unstimulated salivary flow $>$ $0.25 \mathrm{~mL} / \mathrm{min}$; salivary $\mathrm{pH}>6$, good oral conditions (presenting full permanent dentition, no open cavities or deficient restorations, absence of gingivitis and periodontal disease). Other factors taken into consideration were related to the overall health of the volunteer. Pregnant women, patients with systemic diseases and using chronic medication were not eligible to participate. Subjects signed an informed consent document prior to the beginning of the study.

\subsection{Specimen preparation}

Bovine lower incisors were freshly extracted and stored in $2 \%$ formaldehyde solution ( $\mathrm{pH}$ 7.0) for 30 days at room temperature. Teeth were submitted to careful visual inspection in order to detect stains and cracks. If these were detected, the teeth were excluded. Selected teeth were carefully cleaned from gingival tissue using a periodontal curette (Duflex, Duflex do Brasil, Brazil) before being cut. Initially the roots were separated from the crowns using a diamond disk (Diaflex-F, Wilcos do Brasil, Petrópolis, Brazil) by sectioning the cervical portion of the tooth. The crown was used for obtaining enamel slabs and, from the root, dentine slabs were prepared. Then the crowns or roots were fixed in acrylic plaques $(40 \times 40 \times 5 \mathrm{~mm})$ that were placed in the ISOMET Low Speed Saw cutting machine (Buehler Ltda., Lake Bluff, IL, USA). Two diamond disks (XL 12205, $102 \times 0.3 \times 12.7 \mathrm{~mm}$, Extec Corp., Enfield, CT, USA), which were separated by a 4 -mm diameter spacer $(7 \mathrm{~cm}$ diameter, $4 \mathrm{~mm}$ thickness and central role of $1.3 \mathrm{~cm}$ ), were used to cut the slabs ( $300 \mathrm{rpm}$, under refrigeration). One enamel and one dentine slabs $(4 \times 4 \mathrm{~mm})$ were obtained from the flattest portion of each crown or root, respectively, through double sections in the longitudinal and transversal directions. The surface of the slabs was ground flat with water-cooled carborundum discs (320, 600 and 1200 grades of $\mathrm{Al}_{2} \mathrm{O}_{3}$ papers; Buehler, Lake Bluff, IL, USA) and polished with felt paper wet by diamond spray ( $1 \mu \mathrm{m}$; Buehler), resulting in removal of about $100 \mu \mathrm{m}$ depth of the enamel, what was controlled with a micrometer. After polishing, the specimens were cleaned in an ultrasonic device with deionised water for $10 \mathrm{~min}$.

Baseline surface hardness (BSH) determination was performed on all the enamel slabs $(n=230)$ for selection purposes (five indentations; Knoop diamond, $25 \mathrm{~g}, 10 \mathrm{~s}$; HMV-2; Shimadzu Corporation, Tokyo, Japan) (Mean KHN 335.3 \pm 2.4 ). Dentine slabs $(n=230)$ were not submitted to surface hardness analysis since previous studies have revealed that this type of analysis is not accurate for this substrate, considering that hardness is not evenly distributed even in sound dentine (Moron et al., 2013). After that, one third of the (enamel/dentine) surface was covered with nail varnish to create a sound control area. The slabs were subjected to 
the formation of artificial caries lesions by immersion in a solution

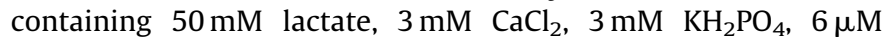
tetraethyl methylene diphosphonate and traces of thymol, $\mathrm{pH}$ 5.0 ( $10 \mathrm{M} \mathrm{KOH}$ to adjust $\mathrm{pH})(30 \mathrm{~mL}$ per block), for 7 days (dentine) and 6 days (enamel), at $37^{\circ} \mathrm{C}$ (Buskes, Christoffersen, \& Arends, 1985). According to a previous pilot study, this protocol produces lesions with mean $( \pm)$ depths of $64.0 \pm 20.1 \mu \mathrm{m}$ and $82.9 \pm 18.9 \mu \mathrm{m}$ for enamel and dentine, respectively.

After demineralisation, surface hardness (SHD) determination was done in enamel slabs and the other outer one third of the surface (enamel/dentine) was protected with nail varnish (demineralised control area). For the ex vivo/in situ experiment, 230 predemineralised enamel and 230 pre-demineralised dentine were randomly allocated into 23 subjects ( $n=2 /$ subject/phase) according to SHD means.

\subsection{Ex vivo/In situ experiment}

Acrylic palatal appliances were constructed individually for each volunteer and for each phase. They were made with four cavities $(5 \times 5 \mathrm{~mm})$, distributed into 2 rows of 2 spaces each. Enamel and dentine slabs were randomly accommodated into the cavities and fixed in place with wax. The study comprised 5 crossover phases of 7 days each, separated among each other by a washout period of 7 days (no treatment) (Afonso et al., 2013). In each phase, four-five volunteers were assigned to one of the five treatments, as follows: T1: fluoridated milk $(0.5 \mathrm{mg} \mathrm{F})$, administered daily ( $200 \mathrm{~mL}$ of milk containing $2.5 \mathrm{ppm} \mathrm{F}$ as $\mathrm{NaF}$ ); T2: fluoridated milk (0.5 mg F), administered every other day; T3: fluoridated milk (1.0 mg F), administered daily $(200 \mathrm{~mL}$ of milk containing $5.0 \mathrm{ppm} \mathrm{F}$ as NaF); T4: fluoridated milk $(1.0 \mathrm{mg} \mathrm{F})$, administered every other day; T5: No treatment. Fluoridated pasteurised whole milk (Batavo Total, BRF SA, Teutônia, RS, Brazil) was prepared by the addition of powdered sodium fluoride (Merck, Darmstadt, Germany). Preparation was done every day and fluoride concentrations were checked using an ion specific electrode, after hexamethyldisiloxane-facilitated diffusion (Taves, 1968).

Dental prophylaxis was done before the ex vivo/in situ phase started in order to remove dental biofilm and also between the ex vivo/in situ periods. The devices were worn by the volunteers $12 \mathrm{~h}$ before starting the treatments and challenges, allowing the salivary pellicle to form. To perform the experiment, in the days that milk should be used (every day for T1 and T3 or every other day for T2 and T4), the volunteers were instructed as follows: in the morning, during breakfast, they were asked to remove the device from the mouth and to immerse it in a cup containing $100 \mathrm{~mL}$ of milk for $5 \mathrm{~min}$. Then they were asked to drink $200 \mathrm{~mL}$ of milk and reinsert the device in the mouth immediately after (Malinowski et al., 2012a). Palatal devices were used during the entire day, except when drinking or eating (in total $4 \mathrm{~h} /$ day). The devices were kept in wet gauze inside a plastic container during the time they were not being used by the volunteers. It is important to highlight that the study was conducted in a fluoridated area $(0.6-0.8 \mathrm{ppm})$ (Buzalaf et al., 2013), but the volunteers drank bottled water with low fluoride concentration $(<0.2 \mathrm{ppm})$ provided by the researchers throughout the experimental period. The same water was used for cooking and preparing beverages. The volunteers were instructed to keep their usual eating habits and to perform oral hygiene using toothbrush, dental floss and non-fluoridated toothpaste provided by the researchers during all stages of the study. Only the surface of the device that was in contact with the palate could be brushed. The volunteers were also instructed not to use any type of fluoride or antibacterial products during the ex vivo/in situ period. At the end of each phase, the devices of all volunteers were collected and washed with deionised water and the slabs were again set on their respective acrylic discs to be prepared for hardness and transverse microradiography (TMR) analysis.

\subsection{Hardness measurement}

After the ex vivo/in situ phase, final surface hardness (FSH) analysis was performed on all the enamel slabs as described above. The \% surface hardness recovery (\%SHR) was calculated, as follows: $\%$ SHR $=[(\text { FSH }- \text { SHD }) /(\text { BSH }- \text { SHD })]^{*} 100$.

\subsection{Transverse microradiography}

Two longitudinal sections were made at the center of the block. Each piece had a thickness of approximately $1.3 \mathrm{~mm}$. The cut was perpendicular to the orientation of the protective nail polish. Thus, $1 / 3$ of the surface corresponded to sound enamel (or dentine), $1 / 3$ to enamel (or dentine) artificially demineralized and $1 / 3$ to enamel (or dentine) after in situ remineralisation. After cutting, $1 / 3$ of the block was used for TMR analysis, while the remainder was stored in eppendorf tubes filled with deionised water for future analyses, if necessary. Fragments were then hand polished to obtain a specimen of an approximate thickness of $100 \mu \mathrm{m}$ using watercooled silicon-carbide discs (600-and 1200-grade papers ANSI grit; Buehler, Enfield, CT, USA). The final thickness of each specimen was checked with a micrometer. The dentine specimens were immersed in ethylene glycol (Sigma-Aldrich, Steinheim, Germany) for $24 \mathrm{~h}$ before exposure to avoid shrinkage during X-ray exposure due to desiccation (Buchalla, Attin, Roth, \& Hellwig, 2003). After that, the specimens were bonded with adhesive tape on the sample holder (around 30-40 samples/specimen holder), containing the aluminium calibration step wedge with different thicknesses, which generates different shades of grey. Then the sample holder was inserted into the cassette with the glass plate in a dark room. The cassette was placed inside a black bag and taken to the X-ray generator (Softex, Japan). The glass plate was sensitized by $\mathrm{x}$-ray ( $20 \mathrm{kV}$ and $20 \mathrm{~mA}$ for enamel and $20 \mathrm{kV}$ and $15 \mathrm{~mA}$ for dentine) for $20 \mathrm{~min}$. After each exposure, the glass plate was developed for $6 \mathrm{~min}$, fixed for $3 \mathrm{~min}$ in a dark room at $20^{\circ} \mathrm{C}$ and washed with running water for $10 \mathrm{~min}$. The developed plate was analysed using a transmitted light microscope fitted with a $20 \times$ objective (Zeiss, Germany), a CCD camera (Canon, Japan) and a computer. The images were taken using data-acquisition (version 2012) and interpreted using calculation (version 2006) software from Inspektor Research System (Amsterdam, The Netherlands). From the analysis of 11 slices of aluminium (step wedge for the construction of "standard curve") and for each microradiogram, it was possible to calculate the integrated mineral loss $(\Delta \mathrm{Z})$ and lesion depth $(\mu \mathrm{m})$ using the formula by Angmar, Carlstrom, and Glas (1963). The $\Delta Z$ (vol $\mu \mathrm{m} \%)$ is the product of the difference between the percentage of mineral volume of sound enamel or dentine and the percentage of mineral volume of demineralised enamel or dentine in relation to the depth of the lesion $(\mu \mathrm{m})$. The depth of the lesion (LD) is defined by the distance from the surface ( $0 \mathrm{vol} \% \mathrm{~min}$ ) to the depth at which the enamel/dentine again has a mineral content equal or greater than $95 \%$ of the mineral content of sound enamel/dentine (Arends \& ten Bosch, 1992). The mineral volume of the sound enamel and dentine corresponds to $87 \%$ and $50 \%$, respectively. To calculate the value obtained at the end of the treatments, the $\Delta \Delta \mathrm{Z}$ and $\Delta \mathrm{L}$ was calculated as the difference between $\Delta \mathrm{Z}$ lesion $-\Delta \mathrm{Z}$ treatment and $\mathrm{L}$ lesion $-\mathrm{L}$ treatment, respectively (after treatments $\mathrm{T} 1 / \mathrm{T} 2 / \mathrm{T} 3 / \mathrm{T} 4 / \mathrm{T} 5$ ). For enamel the mean baseline of integrated mineral loss ( $\Delta \mathrm{Z}$ lesion) and (L lesion), respectively, were: T1 ( $\Delta$ Z 1725.6/L 58.9); T2 ( $\Delta$ Z 2047.4/L 67.4); T3 ( $\Delta$ Z 2075.9/L 63.5); T4 ( $\Delta$ Z1898.7/L 58.7); T5 ( $\Delta$ Z 2277.8/L 70.3). For dentin they were: T1 ( $\Delta \mathrm{Z} 2223.2 / \mathrm{L} 88.3)$; T2 ( $\Delta \mathrm{Z}$ 3224.2/L 79.1); T3 ( $\Delta$ Z 1333.7/L 64.3); T4 ( $\Delta$ Z1846.1/L 80.8); T5 ( $\Delta$ Z 2152.8/L 92.9). 


\subsection{Statistical analysis}

The software GraphPad InStat (version 3.0) was used. Initially, data were tested for normality and homoscedasticity, using Kolmogorov-Smirnov and Bartlett's tests, respectively. Data regarding \%SHR for enamel, and $\Delta \Delta \mathrm{Z}$ for enamel and dentine were analysed by one-way, repeated-measures ANOVA and Tukey's post-hoc test. Data regarding lesion depth were analysed by Friedman's test (non-parametric repeated-measures ANOVA) and Dunn's multiple comparison test. In all conditions, the sample number was the number of volunteers and the significance level was set at $5 \%$.

\section{Results}

Two volunteers were not able to finish all phases of the study ex vivo/in situ and were excluded. One of them left the study on the second experimental phase because he reported to have difficulties to drink plain milk. The other one left the study on the fifth experimental phase because he had to move to another city.

Mean \%SHR of enamel slabs with artificial caries lesions after in situ remineralisation is presented in Table 1. Repeated-measures ANOVA found a significant difference among the treatments $(\mathrm{Fr}=3691, \mathrm{p}=0.0081)$. No dose-response was observed for the two fluoride concentrations in milk evaluated, regardless the frequency of intake. The highest \%SHR was found for the groups treated with fluoridated milk daily, regardless the amount of F (T1 and T3) that did not significantly differ from each other but performed significantly better than T5 (no treatment). Treatments with fluoridated milk every other day (T2 and T4) presented an intermediate effect and were not significantly different from $\mathrm{T} 1$, T3 and T5.

For enamel, significant differences were found among the groups for $\Delta \Delta \mathrm{Z}(\mathrm{Fr}=18.647, \mathrm{p}=0.0009)$. All groups showed positive values of $\Delta \Delta Z$, which means remineralisation, except for T4 that showed negative values (demineralisation). The two groups with the highest remineralisation (T1 and $\mathrm{T} 3$ ) were significantly different from T4. The differences among the other groups were not significant. The same pattern was found for the lesion depth, but in this case the differences among the groups were not significant $(\mathrm{Fr}=8.988, \mathrm{p}=0.061)$ (Table 2 ).

For dentine, no significant differences among the groups were found for lesion depth $(\mathrm{Fr}=4.985, \mathrm{p}=0.289)$. The results found for $\Delta \Delta \mathrm{Z}$ were quite different from those obtained for enamel. A significant difference was found among the groups (repeatedmeasures ANOVA, $\mathrm{Fr}=3.75, \mathrm{p}=0.010$ ). The only group that presented remineralisation was $\mathrm{T} 2$ that was significantly different from all the others that suffered demineralisation (Table 3 ).

Table 1

Mean percentage of surface hardness recovery (\%SHR) of enamel slabs with artificial caries lesions remineralised in situ, as function of treatment with fluoridated milk containing 2.5 or $5.0 \mathrm{ppm}$ fluoride every day or every other day.

\begin{tabular}{llllll}
\hline & \multicolumn{2}{l}{ Treatments } & & & \\
\cline { 2 - 6 } & T1 & T2 & T3 & T4 & T5 \\
\hline Mean & $9.4^{\mathrm{a}}$ & $8.6^{\mathrm{ab}}$ & $9.7^{\mathrm{a}}$ & $8.8^{\mathrm{ab}}$ & $5.1^{\mathrm{b}}$ \\
$S D$ & 5.3 & 5.2 & 5.5 & $3.5^{2}$ & 4.8 \\
\hline
\end{tabular}

Different superscript letters indicate significant differences among the treatments $(n=22)$. Repeated-measures ANOVA and Tukey's test $(\mathrm{p}<0.05) . \mathrm{T} 1$ : fluoridated milk (2.5 ppm F) every day; T2: fluoridated milk ( $2.5 \mathrm{ppm} \mathrm{F})$ every other day; T3: fluoridated milk (5.0 ppm F) every day; T4: fluoridated milk (5.0 ppm F) every other day; T5: no treatment.
Table 2

Average lesion depth ( $\mu \mathrm{m}, \pm \mathrm{SD} ; \Delta \mathrm{L}=\mathrm{L}$ lesion $-\mathrm{L}$ treatment $)$ and integrated mineral loss ( $\Delta \Delta \mathrm{Z} ; \Delta \mathrm{Z}$ lesion $-\Delta \mathrm{Z}$ treatment) for the enamel slabs with artificial caries lesions submitted to in situ remineralisation, as function of treatment with fluoridated milk containing 2.5 or 5.0 ppm fluoride every day or every other day.

\begin{tabular}{lll}
\hline Treatment & $\Delta \mathrm{L}-$ depth $(\mu \mathrm{m})$ & $\Delta \Delta \mathrm{Z}(\mathrm{vol} \mu \mathrm{m} \%)$ \\
\hline T1 & $6.5 \pm 9.2$ & $247.3 \pm 198.5^{\mathrm{a}}$ \\
T2 & $2.3 \pm 8.7$ & $110.9 \pm 303.2^{\mathrm{ab}}$ \\
T3 & $0.9 \pm 10.2$ & $226.0 \pm 299.2^{\mathrm{a}}$ \\
T4 & $-5.2 \pm 9.0$ & $-274.5 \pm 407.3^{\mathrm{b}}$ \\
T5 & $3.5 \pm 6.6$ & $5.0 \pm 288.0^{\mathrm{ab}}$ \\
\hline
\end{tabular}

No significant differences were detected among the treatments for $\Delta \mathrm{L}$ (Friedman's test, $\mathrm{p}>0.05$ ). For $\Delta \Delta \mathrm{Z}$, distinct lower case letters denote significant differences among the five groups, (repeated-measures ANOVA and Tukey's test, $\mathrm{p}<0.05$ ). T1: fluoridated milk (2.5 ppm F) every day; T2: fluoridated milk (2.5 ppm F) every other day; T3: fluoridated milk (5.0 ppm F) every day; T4: fluoridated milk (5.0 ppm F) every other day; T5: no treatment. $n=17$.

\section{Table 3}

Average lesion depth ( $\mu \mathrm{m}, \pm \mathrm{SD} ; \Delta \mathrm{L}=\mathrm{L}$ lesion $-\mathrm{L}$ treatment ) and integrated mineral loss ( $\Delta \Delta \mathrm{Z} ; \Delta \mathrm{Z}$ lesion $-\Delta \mathrm{Z}$ treatment) for the dentine slabs with artificial caries lesions submitted to in situ remineralisation, as function of treatment with fluoridated milk containing 2.5 or 5.0 ppm fluoride every day or every other day.

\begin{tabular}{lll}
\hline Treatment & $\Delta \mathrm{L}-\operatorname{depth}(\mu \mathrm{m})$ & $\Delta \Delta \mathrm{Z}(\mathrm{vol} \mu \mathrm{m} \%)$ \\
\hline T1 & $-3.2 \pm 6.8$ & $-117.9 \pm 344.8^{\mathrm{a}}$ \\
T2 & $3.1 \pm 16.0$ & $350.0 \pm 657.5^{\mathrm{b}}$ \\
T3 & $1.3 \pm 11.1$ & $-182.7 \pm 269.5^{\mathrm{a}}$ \\
T4 & $1.8 \pm 10.0$ & $-185.0 \pm 360.3^{\mathrm{a}}$ \\
T5 & $-0.6 \pm 7.5$ & $-127.0 \pm 332.3^{\mathrm{a}}$ \\
\hline
\end{tabular}

No significant differences were detected among the treatments for $\Delta \mathrm{L}$ (Friedman's test, $\mathrm{p}>0.05$ ). For $\Delta \Delta \mathrm{Z}$, distinct letters denote significant differences among the groups (repeated-measures ANOVA and Tukey's test, $\mathrm{p}<0.05)$. T1: F-milk $(2.5 \mathrm{ppm}$ F) every day; T2: F-milk (2.5 ppm F) every other day; T3: F-milk (5.0 ppm F) every day; T4: F-milk (5.0 ppm F) every other day; T5: no treatment. $n=13$.

\section{Discussion}

Despite fluoridated milk has been recommended as an alternative vehicle to deliver fluoride since 1953 and some clinical studies have attested the preventive effect of this measure to prevent caries, evidence on this regard has not been firmly established so far (Cagetti et al., 2013; Yeung et al., 2005). Recently, various mechanistic studies have attempted to contribute to a better understanding of the effect of fluoridated milk against caries, using in vitro and in situ models. These studies have evaluated different parameters, such as fluoride concentration in milk (Giacaman, Munoz, Ccahuana-Vasquez, Munoz-Sandoval, \& Cury, 2012; Itthagarun et al., 2011 ; Lippert, Martinez-Mier, \& SotoRojas, 2012; Lippert et al., 2014; Malinowski et al., 2012a; Malinowski, Duggal, Strafford, \& Toumba, 2012b), temperature of milk (Lippert et al., 2012), volume of ingested milk (Lippert et al., 2014) and frequency of milk ingestion (Ongtenco et al., 2014) on the anticariogenic properties of fluoridated milk. In general, in vitro studies have reported that milk containing $2.5 \mathrm{ppm}$ fluoride significantly increases enamel remineralisation and that increasing fluoride concentrations do not have an additive effect (Itthagarun et al., 2011; Malinowski et al., 2012b). Additionally, the use of fluoridated milk twice per day remineralised enamel lesions in vitro to a greater extent when compared with the use once per day or every other day (Ongtenco et al., 2014). Despite in vitro models are broadly employed to evaluate the anticariogenic effect of different treatments (Buzalaf et al., 2010), some very important variables such as the presence of saliva can be more precisely reproduced using in situ designs (Cochrane, Zero, \& Reynolds, 2012). This is the first ex vivo/in situ study to evaluate the remineralising potential of milk with different fluoride concentrations and frequencies of use on both enamel and dentine. 
The fluoride concentrations (2.5 and $5.0 \mathrm{ppm}$ ) were chosen because they are the most used in milk fluoridation schemes worldwide, where $200 \mathrm{~mL}$ of milk containing 0.5 or $1.0 \mathrm{mg}$ fluoride is typically offered to children in school based programmes, depending on the age and background exposure to fluoride (Banoczy et al., 2013). The frequencies of milk intake (every day or every other day) were chosen to mimic the provision of milk to school children every day, as happens in some schemes (Marino, Villa, \& Guerrero, 2001) or on school days only (around 200 days per year), which is the case for most of the milk fluoridation programmes. The immersion of the appliance in milk for five minutes was chosen based on a previous study conducted by Malinowski et al., (2012a), and it was included in the study to establish the same time of application for all volunteers, once there are those who ingest beverages faster than others. Our control group received no treatment instead of milk, since there is no programme offering non-fluoridated milk in order to prevent dental caries. Additionally, plain milk (without fluoride) has been shown to have rehardening effect similar to milk containing $1.5 \mathrm{mg}$ fluoride (Lippert et al., 2014). In addition, fluoridated milk (5.0 ppm fluoride) was not significantly different from non-fluoridated milk regarding dentine demineralisation (Giacaman et al., 2012).

Since the aim of the present study was to assess the remineralising potential of fluoridated milk, enamel and dentine slabs with artificially produced caries lesions were used. The protocol of artificial demineralisation used was shown to produce caries lesions at early stages, in line with previous studies using different protocols, both for enamel (Buskes et al., 1985; Magalhaes et al., 2009) and dentine (Moron et al., 2013). This type of lesion allowed studying the influence of the treatments on the remineralization of incipient caries lesions. The in situ remineralisation period chosen ( 7 days) was based on the study by Afonso et al. (2013). In that study, the authors tested remineralisation periods of 3 and 7 days when fluoridated dentifrices (0-1100 ppm) were used, using surface and cross-sectional hardness as response variables. They observed more pronounced dose-response relationship for the lesions remineralised for 3 days than for those remineralised for 7 days. However, the fluoride concentrations used ranged between 0 and $1100 \mathrm{ppm}$ delivered in dentifrices. In the present study, since the fluoride concentrations in milk were much lower, volunteers drank non-fluoridated water and used a fluoride-free dentifrice throughout the experimental period, we decided to use 7 days of experimental period, in order to increase the extent of remineralisation. The degree of remineralisation, however, was low.

For enamel specimens, \%SHR ranged between 5 and $10 \%$. However, it was possible to see a significant increase in \%SHR for the groups treated with fluoridated milk daily (T1 and T3), regardless the fluoride concentration in milk, without significant differences between these groups. These results were reflected in the subsurface of the lesions, where the highest degrees of remineralisation were seen for $\mathrm{T} 1$ and $\mathrm{T} 3$ (Table 2). These results confirm previous in vitro studies that revealed that milk containing $2.5 \mathrm{ppm}$ fluoride significantly increases enamel remineralisation and that increasing fluoride concentrations do not have an additive effect (Itthagarun et al., 2011; Malinowski et al., 2012b). It is important to highlight that only when milk was used daily it was possible to see significant enamel remineralisation in comparison to control (no treatment). This is in agreement with recent in vitro findings (Ongtenco et al., 2014) and is also in-line with the current knowledge regarding the mechanism of action of fluoride for caries control that emphasises the need of constant low-fluoride levels of fluoride in the oral fluids (Buzalaf, Pessan, Honorio, \& ten Cate, 2011 ). It should be noted again that the degree of remineralisation, both at the surface and in deeper layers of enamel, was low. This might have been due to the low fluoride concentration in milk
(2.5-5.0 ppm, compared to $1000 \mathrm{ppm}$ when fluoride is included in dentifrice formulations) and low exposure to fluoride from other sources, since volunteers used fluoride-free dentifrice and drank bottled water with low fluoride concentration throughout the experimental period.

Current milk fluoridation programmes are directed to school children and, due to this, nearly all studies in the literature focus on the potential of fluoridated milk to control enamel caries. In the present study we decided to evaluate also the protective effect of fluoridated milk against dentine caries because milk fluoridation schemes could be implemented to older people that might suffer both from dentine caries (due to gingival recession) (Petersson, Magnusson, Hakestam, Baigi, \& Twetman, 2011) and osteoporosis and could benefit from fluoridated milk. The results found for dentine, however, were remarkably different from that observed for enamel. Notably, remineralisation was only observed for the group that was treated with the lowest fluoride concentration $(2.5 \mathrm{ppm})$ every other day (T2). The information available in the literature on the effect of fluoridated milk on dentine caries is quite scarce, which limits data interpretation. The only studies available in the literature were conducted in vitro. One of them employed an $S$. mutans biofilm model with $\mathrm{pH}$ cycles. The authors observed that fluoridated milk (5 ppm fluoride) was not significantly different from milk alone regarding dentine demineralisation, while it was for enamel demineralisation. It was also noted that while fluoridated milk did not significantly differ from the positive control $(0.05 \% \mathrm{NaF})$ regarding enamel demineralisation, for dentine fluoridated milk had a worse performance when compared with the positive control. The authors attributed this to the less mineralised nature of the dentinal tissue (Giacaman et al., 2012). The other study observed that fluoridated milk had a protective effect on root dentine remineralisation, but the effect of a sodium chloride solution was better (Arnold et al., 2014). In the present study, we employed dentine slabs with artificial caries lesions that are expected to contain a superficial layer of demineralised organic matrix (Buzalaf, Kato, \& Hannas, 2012; Tjaderhane et al., 1998). It is possible that the distinct components of milk, such as fat or proteins, have interacted with this organic layer and interfered with the fluoride, since the only group that experience remineralisation was T2, with the lowest fluoride concentration and frequency. However, this does not explain why T4 (5.0 ppm fluoride milk applied every other day) did not suffer remineralisation. Interestingly, for enamel T4 was the only group that had additional demineralisation during the in situ period. Since the present study is the only one that dealt with dentine remineralisation by fluoridated milk so far, additional studies are necessary to confirm and explain our findings.

\section{Conclusion}

The hyphothesis formulated in the present study was partially accepted. Our data suggest that use of fluoridated milk daily seems to have better remineralising effect on enamel than its use every other day (situation that mimics use of fluoridated milk on school days only). Additional clinical studies should confirm the findings. If the results are similar, then current milk fluoridation programmes should consider the need to provide fluoridated milk to children for daily use, instead of use on school days only. Dentine, however, does not seem to benefit from every day use of fluoridated milk, which needs confirmation by further studies.

\section{Conflict of interest}

The authors declare no conflict of interest. 


\section{Role of authors}

Conceived and designed the study: MARB, ACM, JPP; Performed the experiments: LPSC, LC, FL, CC, AD, MM, LG; Analyzed the data: LPSC, MARB, ACM; Drafted the manuscript: LPSC, JPP, ACM, MARB; Read the manuscript: all the authors.

\section{Acknowledgements}

This study was supported by The Borrow Foundation. The authors thank CAPES for the concession of a Master scholarship to the first author.

\section{References}

Afonso, R. L., Pessan, J. P., Igreja, B. B., Cantagallo, C. F., Danelon, M., \& Delbem, A. C (2013). In situ protocol for the determination of dose-response effect of lowfluoride dentifrices on enamel remineralization. Journal of Applied Oral Science 21(6), 525-532.

Angmar, B., Carlstrom, D., \& Glas, J. E. (1963). Studies on the ultrastructure of dental enamel: Iv. The mineralization of normal human enamel. Journal of Ultrastructure Research, 8, 12-23.

Arends, J., \& ten Bosch, J. J. (1992). Demineralization and remineralization evaluation techniques. Journal of Dental Research, 71, Spec No: 924-928.

Arnold, W. H., Heidt, B. A., Kuntz, S., \& Naumova, E. A. (2014). Effects of fluoridated milk on root dentin remineralization. PloS One, 9(8), e104327.

Banoczy, J., Rugg-Gunn, A., \& Woodward, M. (2013). Milk fluoridation for the prevention of dental caries? Acta Medica Academica, 42(2), 156-167.

Bratthall, D., Hansel-Petersson, G., \& Sundberg, H. (1996). Reasons for the caries decline: What do the experts believe? Europea Journal of Oral Sciences, 104, 416422.

Buchalla, W., Attin, T., Roth, P., \& Hellwig, E. (2003). Influence of olive oil emulsions on dentin demineralization in vitro? Caries Research, 37(2), 100-107.

Buskes, J. A., Christoffersen, J., \& Arends, J. (1985). Lesion formation and lesion remineralization in enamel under constant composition conditions. A new technique with applications. Caries Research, 19(6), 490-496.

Buzalaf, M. A., Hannas, A. R., Magalhaes, A. C., Rios, D., Honorio, H. M., \& Delbem, A. C. (2010). Ph-cycling models for in vitro evaluation of the efficacy of fluoridated dentifrices for caries control: Strengths and limitations? Journal of Applied Oral Science, 18(4), 316-334.

Buzalaf, M. A., Pessan, J. P., Honorio, H. M., \& ten Cate, J. M. (2011). Mechanisms of action of fluoride for caries control. Monographs in Oral Science, 22, 97-114.

Buzalaf, M. A., Kato, M. T., \& Hannas, A. R. (2012). The role of matrix metalloproteinases in dental erosion. Advances in Dental Research, 24(2), 72-76.

Buzalaf, M. A., Moraes, C. M., Olympio, K. P., Pessan, J. P., Grizzo, L. T., Silva, T. L., et al (2013). Seven years of external control of fluoride levels in the public water supply in Bauru, Sao Paulo, Brazil. Journal of Applied Oral Science, 21(1), 92-98.

Cagetti, M. G., Campus, G., Milia, E., \& Lingstrom, P. (2013). A systematic review on fluoridated food in caries prevention. Acta Odontologica Scandinavica, 71(3-4), $381-387$
Cochrane, N. J., Zero, D. T., \& Reynolds, E. C. (2012). Remineralization models. Advances in Dental Research, 24(2), 129-132.

Giacaman, R. A., Munoz, M. J., Ccahuana-Vasquez, R. A., Munoz-Sandoval, C., \& Cury, J. A. (2012). Effect of fluoridated milk on enamel and root dentin demineralization evaluated by a biofilm caries model. Caries Research, 46(5), 460-466.

Itthagarun, A., Verma, S., Lalloo, R., King, N. M., Wefel, J. S., \& Nair, R. G. (2011). Effects of fluoridated milk on artificial enamel carious lesions: A ph cycling study. Journal of Dentistry, 39(12), 817-824.

Lippert, F., Martinez-Mier, E. A., \& Soto-Rojas, A. E. (2012). Effects of fluoride concentration and temperature of milk on caries lesion rehardening. Journal of Dentistry, 40(10), 810-813.

Lippert, F., Martinez-Mier, E. A., \& Zero, D. T. (2014). An in situ caries study on the interplay between fluoride dose and concentration in milk. Journal of Dentistry, 42(7), 883-890.

Magalhaes, A. C., Moron, B. M., Comar, L. P., Wiegand, A., Buchalla, W., \& Buzalaf, M. A. (2009). Comparison of cross-sectional hardness and transverse microradiography of artificial carious enamel lesions induced by different demineralising solutions and gels. Caries Research, 43(6), 474-483.

Malinowski, M., Duggal, M. S., Strafford, S. M., \& Toumba, K. J. (2012a). The effect on dental enamel of varying concentrations of fluoridated milk with a cariogenic challenge in situ. Journal of Dentistry, 40(11), 929-933.

Malinowski, M., Duggal, M. S., Strafford, S. M., \& Toumba, K. J. (2012b). The effect of varying concentrations of fluoridated milk on enamel remineralisation in vitro. Caries Research, 46(6), 555-560.

Marino, R., Villa, A., \& Guerrero, S. (2001). A community trial of fluoridated powdered milk in chile. Community Dentistry and Oral Epidemiology, 29(6), 435442.

McDonagh, M. S., Whiting, P. F., Wilson, P. M., Sutton, A. J., Chestnutt, I., Cooper, J., et al. (2000). Systematic review of water fluoridation. British Medical Journal, 321 (7265), 855-859.

Moron, B. M., Comar, L. P., Wiegand, A., Buchalla, W., Yu, H., Buzalaf, M. A., et al. (2013). Different protocols to produce artificial dentine carious lesions in vitro and in situ: Hardness and mineral content correlation. Caries Research, 47(2), $162-170$.

Ongtenco, K. L., Anthonappa, R. P., Itthagarun, A., King, N. M., Lalloo, R., \& Nair, R. G. (2014). Remineralization of initial enamel carious lesions using fluoridated milk in vitro. Acta Odontologica Scandinavica, 72(8), 737-744.

Pessan, J. P., Toumba, K. J., \& Buzalaf, M. A. (2011). Topical use of fluorides for caries control. Monographs in Oral Science, 22, 115-132.

Petersson, L. G., Magnusson, K., Hakestam, U., Baigi, A., \& Twetman, S. (2011). Reversal of primary root caries lesions after daily intake of milk supplemented with fluoride and probiotic lactobacilli in older adults. Acta Odontologica Scandinavica, 69(6), 321-327.

Sampaio, F. C., \& Levy, S. M. (2011). Systemic fluoride. Monographs in Oral Science, 22, $133-145$.

Taves, D. R. (1968). Separation of fluoride by rapid diffusion using hexamethyldisiloxane. Talanta, 15(9), 969-974.

Tjaderhane, L., Larjava, H., Sorsa, T., Uitto, V. J., Larmas, M., \& Salo, T. (1998). The activation and function of host matrix metalloproteinases in dentin matrix breakdown in caries lesions. Journal of Dental Research, 77(8), 1622-1629.

Yeung, C. A., Hitchings, J. L., Macfarlane, T. V., Threlfall, A. G., Tickle, M., \& Glenny, A. M. (2005). Fluoridated milk for preventing dental caries. The Cochrane Database of Systematic ReviewCD003876. 